\title{
B Cell Dysfunction Associated With Aging and Autoimmune Diseases
}

\author{
Shiliang Ma, Chengwei Wang, Xinru Mao and Yi Hao* \\ Department of Pathogen Biology, School of Basic Medicine, Tongji Medical College, Huazhong University of Science and \\ Technology, Wuhan, China
}

Impaired humoral responses, as well as an increased propensity for autoimmunity, play an important role in the development of immune system dysfunction associated with aging. Accumulation of a subset of atypical B cells, termed age-associated B cells (ABCs), is one of the key age-related changes in B cell compartments. ABCs are characterized by their distinct phenotypes, gene expression profiles, special survival requirements, variations in B cell receptor repertoires, and unique functions. Here, we summarize recent progress in the knowledge base related to the features of ABCs, their potential role in immune senescence, and their relationship with autoimmune diseases.

Keywords: aging, autoimmunity, BCR repertoires, T-bet, B cells

\section{OPEN ACCESS}

Edited by:

Tae Jin Kim

Sungkyunkwan University,

South Korea

Reviewed by:

Christopher Sundling,

Karolinska Institute (KI), Sweden

Bruce David Mazer

Research Institute of the McGill

University Health Center, Canada

*Correspondence:

Yi HaO

haoyi@hust.edu.cn

Specialty section:

This article was submitted to

B Cell Biology,

a section of the journal

Frontiers in Immunology

Received: 31 August 2018 Accepted: 06 February 2019 Published: 27 February 2019

Citation:

Ma S, Wang C, Mao $X$ and Hao $Y$ (2019) B Cell Dysfunction Associated

With Aging and Autoimmune

Diseases. Front. Immunol. 10:318.

doi: 10.3389/fimmu.2019.00318

\section{INTRODUCTION}

Humoral immune responses mediated by B cells are important for adaptive immunity. B cells produce a diverse set of antibodies, which help in effectively eliminating antigens including pathogens. In addition, B cells play an indispensable role in the immune system via presentation of antigens and secretion of cytokines (1-3). Aging is a complex process accompanied by a functional decline in multiple physiological systems. In aged individuals, a spectrum of immune system alterations, termed "immune senescence," result in a blunted adaptive immune response, an increased tendency for inflammatory responses, enhanced susceptibility to infections, and an increased production of autoantibodies (4-7). Multiple factors may contribute to these immune activity changes. $T$ cells have been shown to participate in immune senescence. However, the role of B cells in this respect remains unclear. Recent findings illustrate conspicuous shifts in B cell subsets in the elderly, suggesting that age-related changes in B cells may contribute to immune senescence (8-10). The discovery of a subset of B cells, termed age-associated B cells (ABCs), has drawn significant attention in recent years. Initially isolated from aged donors and found to be closely associated with immune senescence, these cells were expected to provide a novel therapeutic avenue for autoimmune diseases. With due consideration to various aspects of their potential, we review previous findings and provide an insight into the properties, functions, and related signaling pathways, which may assist in developing a better understanding of this subset of B cells (Table 1).

\section{CHANGES IN B CELL COMPARTMENTS DURING AGING}

\section{Impaired B Cell Development in the Bone Marrow With Aging}

Normally, B2 B cell development occurs in a fixed order. Emerging from lymphoid-biased hematopoietic stem cells (HSC), these newly generated cells successively develop into pro-B cells, pre-B cells, and immature B cells in the bone marrow, followed by the exit of immature B cells from the bone marrow and completion of maturation. The mature B cells are composed of two peripheral pools: marginal zone B cells and follicular B cells (2). Different subsets of B cells have unique functions in the human body and contribute to the balance and efficacy of immune response. 
TABLE 1 | Properties of ABCs in aging and in autoimmune diseases.

\begin{tabular}{|c|c|c|}
\hline & In aging & In autoimmune diseases \\
\hline Described in & Mice $(4,9-12)$ & Mice (10) and patients (13-17) \\
\hline Phenotype & $\begin{array}{l}\text { CD21-/35-CD23- } \\
(4,9,11) \text { and CD11c } \\
\text { CD21 }^{-} \text {T-bet }^{+}(10,12)\end{array}$ & 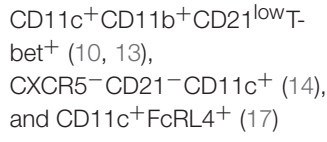 \\
\hline BLyS receptor & $\mathrm{BR3}$ and $\mathrm{TACl}(9)$ & $\begin{array}{l}\text { BR3 }^{\text {high }}, \text { TACl }^{\text {int }} \text {, and } \\
\text { BCMA }^{\text {low }}(13)\end{array}$ \\
\hline $\begin{array}{l}\text { Production of } \\
\text { autoantibody }\end{array}$ & Yes (10) & Yes $(10,13,14)$ \\
\hline $\begin{array}{l}\text { Secretion of } \\
\text { cytokines }\end{array}$ & TNF- $\alpha, I L-4, I L-10(4,9)$ & $\mathrm{N} / \mathrm{A}$ \\
\hline $\begin{array}{l}\text { Presenting } \\
\text { antigens }\end{array}$ & Yes $(9,12)$ & $\mathrm{N} / \mathrm{A}$ \\
\hline $\begin{array}{l}\text { Response to TLR } \\
\text { stimulation }\end{array}$ & $\begin{array}{l}\text { Yes, TLR9, and TLR7 } \\
(9,10)\end{array}$ & Yes, TLR7 $(10,14)$ \\
\hline $\begin{array}{l}\text { Response to BCR } \\
\text { stimulation }\end{array}$ & Poor (9) & $\mathrm{N} / \mathrm{A}$ \\
\hline
\end{tabular}

Although total peripheral B cell counts remain relatively stable in adulthood (8), aging has been associated with a decline in $\mathrm{B}$ cell production in the bone marrow (18). This phenomenon is ascribed to both cell-intrinsic changes and alterations in lymphoid organ microenvironments, which may be interpreted in 3 different ways $(19,20)$. Firstly, analysis of clonal composition of hematopoietic stem cells (HSCs) from aged mice showed that age-associated switching of HSCs from lymphoid-biased cells to myeloid-biased ones, reduced the source of $B$ cell production (21), which was partly due to PAX5 expression being significantly attenuated in older individuals (22). Secondly, in vitro studies indicated that the ability of pro-B cells to respond to IL-7 was impaired (23) and that the release of IL7 from stromal cells in the bone marrow was decreased due to aging (24). These factors reduce pro-B cell proliferation in the elderly. Thirdly, lower renewal rates and immune efficacy of B lymphocytes are responsible for a decrease in surrogate light chain $(\mathrm{SLC})^{+}$precursor B cells and an accumulation of SLC $^{-} \mathrm{B}$ cells. Two pathways associated with the impaired balance between $\mathrm{SLC}^{+}$pre-B cells and $\mathrm{SLC}^{-}$cells have been corroborated to prove this hypothesis: (1) Inhibitor of DNA binding 2 (ID2) in precursor $\mathrm{B}$ cells increases with age and blocks the activity of E2A, an essential transcription factor regulating the transcription of SLC genes, $\lambda 5$ and VpreB (2527). Diminution of SLC causes the loss of pre-B cell receptors, limiting the expansion and further development of pre-B cells, and reducing the generation of $\mathrm{B}$ cells with normal functions (25). (2) Increased secretion of TNF- $\alpha$ by old follicular B cells (28) induces apoptosis of $\mathrm{SLC}^{+}$pro-B cells in the bone marrow (4), followed by the accumulation of $\mathrm{SLC}^{-} \mathrm{B}$ cells that impede the production of immature B cells (29). The signaling pathways mentioned above indicate that age-related changes in the bone marrow, leading to impaired development, and function of B cells, may facilitate the process of immune senescence (Figure 1).

\section{Accumulation of ABCs in the Periphery During Physiological Aging}

Hao et al. and Rubtsov et al. reported that a novel subset of $B$ cells, termed age-associated B cells (ABCs), accumulated in aged mice $(9,10)$. These $B$ cells first accumulated in the spleen and increased significantly in the bone marrow with age $(4,9)$. $\mathrm{ABC}$ phenotypes are distinct from other B cell subsets. Hao et al. defined $\mathrm{CD}^{-} 3^{-} \mathrm{CD} 21^{-} / 35^{-} \mathrm{CD} 23^{-} \mathrm{B}$ cells as ABCs (9), while Rubtsov et al. described them as CD $11 b^{+} \mathrm{CD} 11 c^{+} \mathrm{B}$ cells (10). These 2 groups found that ABCs expressed similar levels of IgM and lower levels of IgD compared to follicular B cells $(9,10)$. In addition, cell cycle analyses showed that ABCs were quiescent, suggesting that they are not a subset of self-renewing cells (9). Because ABCs were explored using mouse models, the existence of similar cells in aged humans may need confirmation.

More interestingly, B cells with phenotypes similar to that of $\mathrm{ABCs}$ appear in both mice and humans, during the course of certain autoimmune diseases $(10,13,14)$, and following some viral infections $(30,31)$. In this review, we focus on $\mathrm{ABCs}$ or ABC-like cells related to aging and autoimmune diseases. However, the existence of similarities between the roles played by these virus-induced $\mathrm{ABC}$-like cells and $\mathrm{ABCs}$ found in aged individuals, may require further investigation.

\section{Altered B Cell Receptor Repertoires of the ABCs}

$B$ cell receptors (BCRs) are immunoglobulins expressed on $B$ cell surfaces and the development of BCR repertoires is associated with the entire B cell life span (3). Primary B cell pools with great diversity are formed following development in the bone marrow. Immature $\mathrm{B}$ cells which leave the bone marrow continue to undergo selection based on BCR specificity. Following stimulation by antigens, mature B cells form germinal centers, in which positive selection and somatic hyper mutations occur. These B cells with high-affinity BCR will out-compete other B cells for survival signals in the germinal center (32). Class-switching can change the isotype of an antibody from IgM/IgD to IgG/IgA/IgE. Some B cells experience class-switching in the germinal centers, but such switching may also occur before the formation of germinal centers (33). These processes make the BCR repertoires more diverse and effective in their immune response. Meanwhile, B cell selections in the bone marrow and the peripheral lymphoid organs contribute to lower autoimmunity (34).

Considering that BCRs form the basis of antigen recognition by $B$ cells, and that its sustained signaling is required for the survival of both immature and mature B cells (35), BCR repertoires are of vital importance for directing intrinsic immune responses appropriately. Thus, it may be vital to explore the properties of BCRs of ABCs. However, only a few studies have focused on this aspect. It has been shown that mutation of $\mathrm{VH}$ and $V \kappa$ in $A B C s$ was increased compared to that in follicular and marginal zone B cells, but at a lower frequency than in germinal center B cells of immunized mice. The mutation of BCRs in ABCs appears to be in the mid range between naïve $B$ cells and germinal center B cells (11). Although these findings indicate altered BCR 


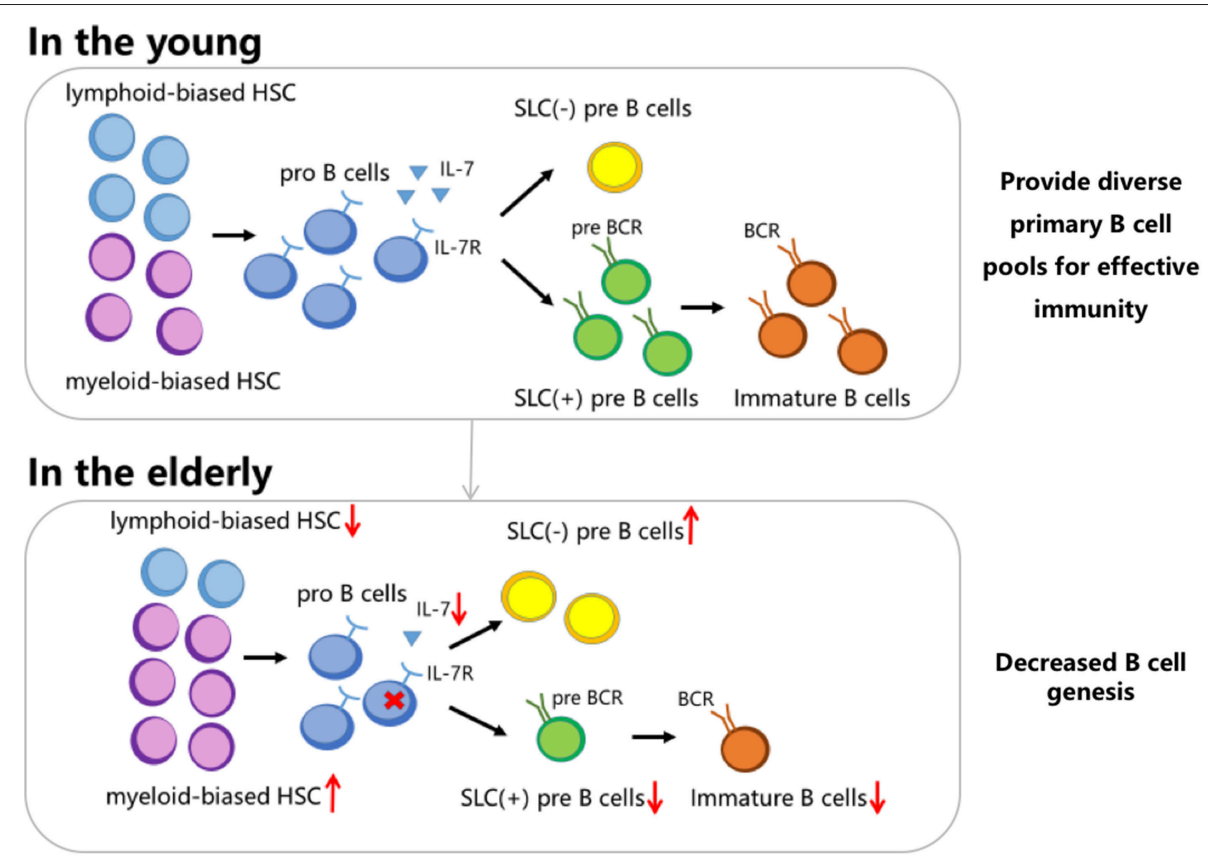

FIGURE 1 | Altered renewal rate of B cells in the bone marrow of the elderly. The phenomenon can be interpreted in three ways. Firstly, HSC switch from lymphoid-biased to myeloid-biased with aging. Secondly, the ability of aged pro-B cells to respond to IL-7 is impaired, and the release of IL-7 from stromal cells in the bone marrow is decreased. Thirdly, there is a deficit of SLC ${ }^{+}$precursor B cells and an accumulation of SLC ${ }^{-}$cells. $^{-}$

repertoires of $\mathrm{ABCs}$, which may be helpful in understanding the nature of $\mathrm{ABCs}$, further details regarding other characteristics of $\mathrm{BCR}$ repertoires of $\mathrm{ABCs}$ are needed.

\section{Functions of $A B C s$}

$B$ cells are chiefly responsible for maintaining humoral defense. In addition to providing antibodies, B cells produce certain cytokines and present antigens to $\mathrm{CD} 4^{+} \mathrm{T}$ cells. Considering that the proportion of $\mathrm{ABCs}$ tends to increase with age, and that their characteristics are distinct from other B cell subsets, investigating the characteristics of their functions is important. A better understanding of their functions may help in clarifying possible mechanisms underlying immune senescence. Recent studies have demonstrated the potential function of ABCs (Figure 2).

Firstly, unlike follicular B cells, ABCs responded only to TLR7 and TLR9 stimuli in vitro. They were found to secrete antibodies upon TLR stimulation rather than upon BCR stimulation $(9,10)$. Since TLRs are commonly associated with skewing toward inflammatory responses (36), increased numbers of ABCs may yield more innate immune responses, characterized by low-affinity antibody, and inflammatory processes. Furthermore, ABCs directly participate in producing autoantibodies, indicating that they are associated with serious autoimmunity seen in the aged (10).

Secondly, the ability to secrete specific cytokines is also a critical part of $\mathrm{ABC}$ function. ABCs preferentially secrete IL4 and IL-10 upon TLR stimulation in vitro (9), and increase the expression of TNF- $\alpha$ at mRNA level in mice (28). IL-4 could promote $\mathrm{B}$ cell maturation, which may play a role in the altered proportions of different B cell subsets (37). TNF$\alpha$ was associated with a decrease in pro-B cells in the bone marrow. Co-culture of bone marrow cells with splenic ABCs from old mice showed that growth of B cell precursors was inhibited by ABCs. However, inclusion of neutralizing antiTNF- $\alpha$ antibodies, prevented inhibition of $\mathrm{B}$ cell precursor growth by $\mathrm{ABCs}$, indicating that inhibition by $\mathrm{ABCs}$ is mediated by TNF- $\alpha$ (4). Meanwhile, inhibition could also be reversed by caspase 3 inhibitor, demonstrating that TNF- $\alpha$ kills B cell precursors via apoptosis (4). These in vitro studies may provide a reasonable explanation for the reduction of bone marrow $\mathrm{B}$ cells, proportionately to increased $\mathrm{ABC}$ to follicular $\mathrm{B}$ cell ratio. However, relevant in vivo experiments are needed to validate this mechanism. Furthermore, addition of IL-10 rescued the suppression of B cell precursors induced by TNF- $\alpha$ (4). Detailed mechanisms underlying the effect of $\mathrm{ABC}$-derived cytokines on the composition and function of $\mathrm{B}$ cell compartments need to be further evaluated.

Thirdly, ABCs display an enhanced ability to take up, process, and present antigens to T cells. This ability is attributed to their higher levels of MHCII and costimulatory molecules, longer and more stable interactions with $\mathrm{T}$ cells, more expression of genes associated with vesicular transport and cytoskeletal rearrangement and higher levels of CD11c $(10,12)$. In contrast to follicular B cells which are located at B cell follicles, ABCs are localized in either $\mathrm{T}$ cell zones or at $\mathrm{T}$ cell/B cell borders. This is ascribed to the finding that while $\mathrm{ABCs}$ convert from follicular $\mathrm{B}$ cells, CCR7 receptor expression in ABCs is upregulated, increasing their responsiveness to T cell zone chemokines CCL19 


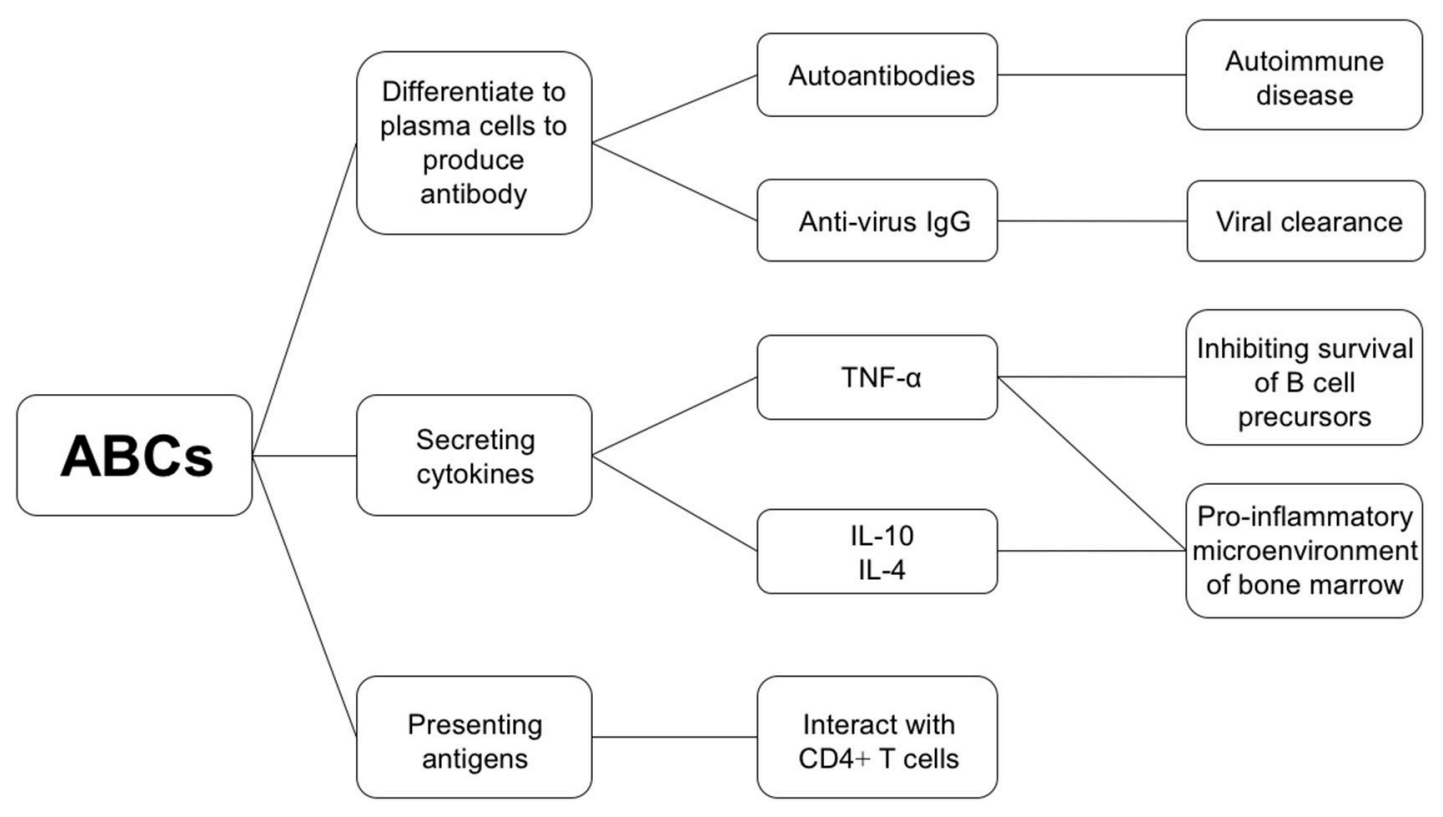

FIGURE 2 | Functional properties of ABCs.

and CCL21, and potentiating their migration toward T cell zones (12). Such special localization causes them to be more competent in interacting with $\mathrm{T}$ cells. As they are capable of presenting antigens efficiently, they may function as antigen-presenting cells in the process of autoimmunity as self-antigen concentrations are usually low.

Considered together, $\mathrm{ABCs}$ appear to play multiple roles in age-associated alteration of immune activity. However, antigenpresentation ability is mainly displayed in in vitro assays. Interaction of $\mathrm{ABCs}$ with the other immune cells in vivo may need further exploration.

\section{Survival of ABCs Is BLyS-Independent, but IL-21 and T-Bet Are Key Factors for the Generation of ABCs}

As discussed above, ABCs are likely involved in impaired immune response associated with aging. Therefore, it is important to determine their precursors, define their homeostatic requirements, and determine factors regulating their generation, as this knowledge may assist in identifying potent targets for clinical application.

In order to determine the origin of $\mathrm{ABCs}$, peripheral $\mathrm{B}$ cell subsets in aged mice were accessed after auto-reconstitution following sublethal irradiation. If $\mathrm{ABCs}$ are produced by aged B lymphopoiesis, auto-reconstitution would result in their replenishment. However, compared with that of untreated aged mice their $\mathrm{ABC}$ level was lower, indicating that $\mathrm{ABC}$ did not directly emanate from $B$ cell genesis in the aged bone marrow (9). Studies have revealed that follicular B cells acquired the ABC phenotype only after extensive proliferation, driven by tolllike receptor (TLR) stimuli alone, or in combination with BCR stimuli, both in vivo and in vitro. This indicated that ABCs may partly originate from exhaustive expansion of mature B cells (9). In vivo studies using mouse models further revealed that generation of $\mathrm{ABCs}$ required endogenous antigen presentation via MHC class II and stimulation via the CD40 receptor (11). In summary, these studies indicate two possible sources of ABCs. One is a TLR-mediated origin, possibly through virus or autoimmune stimulation (30). The other is the accumulation of mature B cells that have undergone environmental antigen stimulation through T-dependent mechanisms.

B lymphocyte stimulator (BLyS) cytokine family, a member of the tumor necrosis factor superfamily, is critical for the survival and homeostasis of mature B cells (38). BLyS family is composed of at least two ligands, BLyS and APRIL, and three receptors, BR3, TACI, and BCMA. Among them, BLyS-BR3 signaling is crucial for naïve mature B cell survival. B cells with a different BLyS binding capacity must compete for limited survival signals $(38,39)$. Compared with other B cell subsets, ABCs seem not to rely on BLyS for survival, although they express BLyS receptors and are able to sequester BLyS (9). In this regard, accumulation of $\mathrm{ABCs}$ may reduce the availability of BLyS for other B cell subsets, gradually insulting adaptive immune response in the elderly and the homeostasis of B cells sustained by BLyS. However, more studies are required to confirm this.

In regard to factors regulating $\mathrm{ABC}$ generation, it has been recently reported that the transcription factor-T-bet, is highly expressed in ABCs (40). T-bet expression in B cells is essential for the production of autoantibodies (41), formation of IgG2a memory, and IgG2a class switching (42). T-bet also participates in the transition to $\mathrm{CD}_{11 c^{+}} \mathrm{B}$ cells, which are major precursors for IgG2a antibody production (30). IgG2a represents the most competent isotype for antibody-dependent 
cellular cytotoxicity (43) and plays an important role in antiviral immune response (44). The signaling system regulating T-bet expression mainly consists of TLR stimulation, BCR stimulation, and related cytokines (45). Among these three factors, TLR stimulation is the most potent inducer, and T-bet expression is the strongest upon simultaneous stimulation by all three factors (30), suggesting that although BCR stimulation and cytokines are not indispensable, they are capable of amplifying the effect mediated by TLR stimulation.

Considering that B cell differentiation could be regulated by certain cytokines, it is interesting to know how specific cytokines affect the generation of $\mathrm{ABCs}$. Evidence suggesting that cytokines play a role in the generation of $\mathrm{ABCs}$ come from both in vitro and in vivo studies by Naradikian et al. (40). The authors cultured follicular B cells from mice or humans with IL-4, IL-21, or IFN- $\gamma$ in the presence of TLR7 or TLR9 agonists. They found that both IL-21 and IFN- $\gamma$ directly promoted ABC production while IL4 antagonized T-bet induction. These interactions of cytokines were also demonstrated in vivo using the influenza virus and $H$. polygyrus infections (40).

Furthermore, using transgenic mouse lupus models, it was demonstrated that interferon-regulatory factor 5 (IRF5) would control the generation of ABCs via stimulation of IL-21 (46). Considered together, both IL-21 and T-bet are key factors for $\mathrm{ABC}$ functioning, indicating great potential for these two factors in applications related to targeted treatment of ABC-associated diseases. Notably, $\mathrm{T}_{\mathrm{FH}}$ cells are important sources of IL-21 (46). Furthermore, studies showed that co-stimulation via the CD40 receptor on $\mathrm{B}$ cells and $\mathrm{CD} 40 \mathrm{~L}$ on $\mathrm{T}$ cells may be important for $\mathrm{ABC}$ generation (11). Thus, the T-B interaction may be required for the generation of ABCs.

\section{ABCs AND AUTOIMMUNE DISEASES}

As mentioned above, ABCs are known to secrete autoantibodies. Elevated levels of serum anti-chromatin IgG2a were observed in mice with cGVHD-induced lupus (47). in vitro studies also showed that ABCs preferentially induced Th17 differentiation (9). It may be important to know whether accumulation of $\mathrm{ABCs}$ plays a role in autoimmune diseases. Examination of mouse autoimmune-prone models (NZB/WF1 and $\mathrm{Mer}^{-/-}$ mice) indicated enhanced $\mathrm{ABC}$ populations (10, 48), raising the issue of whether ABCs lead to autoimmune diseases or emerge as byproducts of the disease process. An indepth study demonstrated that in mouse models subjected to conditional deletion of T-bet, the formation of germinal centers was impaired, serum IgG2a levels were significantly reduced, and kidney damage as well as rapid mortality were inhibited in systemic lupus erythematosus (SLE) mice (49). Similar to the development of ABCs with aging, IL-21 may drive the generation of $\mathrm{T}^{-b}{ }^{+} \mathrm{ABCs}$ in autoimmune models (46). ABCs were also found in SLE patients, which was consistent with similar findings in mouse models (13). While $\mathrm{ABCs}$ in a fraction of these SLE patients expressed IgD, an equal percentage expressed $\operatorname{IgG}$ and $\operatorname{IgA}(13)$, indicating that some ABCs had undergone class-switching. Moreover, these cells could differentiate into plasma cells capable of producing autoantibodies (13). In addition, assessment of somatic hypermutation levels in mouse autoimmune models demonstrated that $\mathrm{ABCs}$ had undergone somatic hypermutation in $\mathrm{VH}$, which exhibited clonal diversification of their $\mathrm{VH}$ genes (50). However, more detailed studies are felt to be required for further substantiation.

These humans and mice studies indicate that increased numbers of $\mathrm{ABCs}$ may contribute to the onset and development of autoimmune diseases, which may be interpreted from two perspectives. On the one hand, TLR stimulation is a well-established factor in autoantibody production and the development of autoimmune diseases $(51,52)$, and ABCs have been found to produce anti-chromatin antibodies upon TLR stimulation in vitro (10). On the other hand, in vitro studies showed that ABCs preferentially skewed activated $\mathrm{CD} 4^{+} \mathrm{T}$ cells to a Th17 fate compared to presentation mediated by young follicular B cells, aged follicular B cells or dendritic cells (9). As Th17s secrete a range of cytokines that amplify inflammatory or autoimmune diseases $(53,54)$, this may enable ABCs to indirectly contribute to autoimmune diseases. More researches are required to validate these hypotheses.

More interestingly, an ABC-like B cell subset, $\mathrm{CXCR}^{-} \mathrm{CD} 21^{-} \mathrm{CD} 11 \mathrm{c}^{+}$, was described in SLE patients (14). These cells, termed double negative 2 cells (DN2 cells), are abundant in SLE patients in an age-independent pattern and capable of differentiating into autoantibody-producing plasma cells which are strongly associated with autoimmune disease (14). Similar to ABCs, DN2 cells express a T-bet transcriptional network and respond intensely to TLR7 stimuli.

Other than ABCs or ABC-like B cells, several novel subsets of $B$ cells related to autoimmune diseases have recently been found. A novel population of memory B cells, which lack expression of CD27 and IgD, were found to be associated with disease activity and clinical manifestations of lupus in SLE patients, (15). Furthermore, CD $19^{\text {hi }} \mathrm{CXCR} 3^{\text {hi }} \mathrm{B}$ cells in SLE are reportedly related to poor clinical outcomes following rituximab treatment (16). FcRL4 ${ }^{+}$B cells produce RANKL, which is associated with bone erosion in rheumatoid arthritis (17). Although associated with different markers, these $\mathrm{B}$ cells likely belong to the same cell type as ABCs, which needs to be confirmed by evaluating the expression of key transcription factor T-bet.

Autoimmune diseases are common diseases that threaten the health of $\sim 23.5$ million (7\%) people in the United States. Women are more commonly affected than men at a significantly lower age of onset (48). Current treatment for autoimmune diseases involve immunosuppressive drugs that dampen immune responses. However, large quantities of normal cells are killed during the treatment process, resulting in lowered resistance against pathogens and higher rates of infection and cancer. Targeted therapies have also been applied to autoimmune diseases. For example, rituximab is a chimeric monoclonal antibody that targets CD20-positive B lymphocytes, leading to B cell depletion. It has been proved effective in rheumatoid arthritis and multiple sclerosis $(55,56)$. These treatments may also kill non-pathogenic B cells. Therefore, it may be important to find alternative targeted therapies. The association between these novel- B cells and 
autoimmune diseases, indicate that these cells may have great potential as therapeutic targets which may be utilized to improve treatment. Further relevant studies are felt to be needed to determine whether $\mathrm{ABCs}$ are the byproduct or the cause of the disease process.

\section{SUMMARY}

Immune cell generation as well as subset composition and function change with age. Alteration of the immune system may contribute to increased morbidity and mortality in the elderly population (57). Age-related changes in B cells are involved in this process. Accumulation of a unique $\mathrm{B}$ cell population that express T-bet, $\mathrm{ABCs}$, is one of the most significant changes in $\mathrm{B}$ cell compartments. $\mathrm{ABCs}$, with their inherent capacity for secreting antibodies, cytokines, and presenting antigens, may play an important role in the complicated signaling network associated with immune senescence. Moreover, ABCs appear to be associated with the onset and development of autoimmune diseases. This indicates the feasibility of ABC-targeted therapeutic approaches. Future research on the properties and functions of $\mathrm{ABCs}$ as well as $\mathrm{ABC}$ associated signaling pathways may assist us to better

\section{REFERENCES}

1. Cooper MD. The early history of B cells. Nat Rev Immunol. (2015) 15:191. doi: $10.1038 /$ nri3801

2. LeBien TW, Tedder TF. B lymphocytes: how they develop and function. Blood (2008) 112:1570. doi: 10.1182/blood-2008-02-078071

3. Yuseff M-I, Pierobon P, Reversat A, Lennon-Duménil A-M. How B cells capture, process and present antigens: a crucial role for cell polarity. Nat Rev Immunol. (2013) 13:475. doi: 10.1038/nri3469

4. Ratliff M, Alter S, Frasca D, Blomberg BB, Riley RL. In senescence, ageassociated B cells secrete TNFalpha and inhibit survival of B-cell precursors. Aging Cell (2013) 12:303-11. doi: 10.1111/acel.12055

5. Ginaldi L, Loreto MF, Corsi MP, Modesti M, Martinis MD. Immunosenescence and infectious diseases. Microbes Infect. (2001) 3:851-7. doi: 10.1016/S1286-4579(01)01443-5

6. Pawelec G. Immunosenescence and vaccination. Immunity Ageing (2005) 2:16. doi: 10.1186/1742-4933-2-16

7. Grubeckloebenstein B, Bella SD, Iorio AM, Michel JP, Pawelec G, Solana R. Immunosenescence and vaccine failure in the elderly. Aging Clin Exp Res. (2009) 21:201-9. doi: 10.1007/BF03324904

8. Blanco E, Perez-Andres M, Arriba-Mendez S, Contreras-Sanfeliciano T, Criado I, Pelak O, et al. Age-associated distribution of normal B-cell and plasma cell subsets in peripheral blood. J Allergy Clin Immunol. (2018) 141:2208-19 e16. doi: 10.1016/j.jaci.2018.02.017

9. Hao Y, O’Neill P, Naradikian MS, Scholz JL, Cancro MP. A B-cell subset uniquely responsive to innate stimuli accumulates in aged mice. Blood (2011) 118:1294-304. doi: 10.1182/blood-2011-01-330530

10. Rubtsov AV, Rubtsova K, Fischer A, Meehan RT, Gillis JZ, Kappler JW, et al. Toll-like receptor 7 (TLR7)-driven accumulation of a novel CD11c(+) B-cell population is important for the development of autoimmunity. Blood (2011) 118:1305-15. doi: 10.1182/blood-2011-01-331462

11. Russell Knode LM, Naradikian MS, Myles A, Scholz JL, Hao Y, Liu $\mathrm{D}$, et al. Age-associated B cells express a diverse repertoire of $\mathrm{VH}$ and Vkappa genes with somatic hypermutation. J Immunol. (2017) 198:1921-7. doi: 10.4049/jimmunol.1601106

12. Rubtsov AV, Rubtsova K, Kappler JW, Jacobelli J, Friedman RS, Marrack P. CD11c-expressing B cells are located at the $\mathrm{T}$ cell/B cell understand the association between $\mathrm{ABCs}$ and aging as well as autoimmunity. It is confirmed that TLR stimulation and related cytokines such as IL-21 are required for the expression of Tbet and generation of ABCs. However, further investigation of detailed survival requirements and functional attributes of $\mathrm{ABCs}$ may be required, to help design optimal clinical procedures to overcome immune senescence and autoimmune diseases in the future.

\section{AUTHOR CONTRIBUTIONS}

SM and $\mathrm{YH}$ determined the topic of the review and designed the structure of the literature. SM, CW, XM, and $\mathrm{YH}$ wrote the manuscript. All authors read the manuscript.

\section{FUNDING}

This work was supported by the National Natural Science Foundation of China (81600160), the Fundamental Research Funds for the Central Universities (HUST: 2015ZHYX007, 2018KFYYXJJ076), the Integrated Innovative Team for Major Human Diseases Program of Tongji Medical College, HUST (500153003). border in spleen and are potent APCs. J Immunol. (2015) 195:71-9. doi: 10.4049/jimmunol.1500055

13. Wang S, Wang J, Kumar V, Karnell JL, Naiman B, Gross PS, et al. IL-21 drives expansion and plasma cell differentiation of autoreactive CD11c(hi)T-bet $(+)$ B cells in SLE. Nat Commun. (2018) 9:1758. doi: 10.1038/s41467-018-03750-7

14. Jenks SA, Cashman KS, Zumaquero E, Marigorta UM, Patel AV, Wang X, et al. Distinct effector B cells induced by unregulated toll-like receptor 7 contribute to pathogenic responses in systemic lupus erythematosus. Immunity (2018) 49:725-39 e6. doi: 10.1016/j.immuni.2018.08.015

15. Wei C, Anolik J, Cappione A, Zheng B, Pugh-Bernard A, Brooks J, et al. A new population of cells lacking expression of $\mathrm{CD} 27$ represents a notable component of the B cell memory compartment in systemic lupus erythematosus. J Immunol. (2007) 178:6624-33. doi: 10.4049/jimmunol.178.10.6624

16. Nicholas MW, Dooley MA, Hogan SL, Anolik J, Looney J, Sanz I, et al. A novel subset of memory B cells is enriched in autoreactivity and correlates with adverse outcomes in SLE. Clin Immunol. (2008) 126:189-201. doi: 10.1016/j.clim.2007.10.004

17. Yeo L, Lom H, Juarez $M$, Snow $M$, Buckley $C D$, Filer $A$, et al. Expression of FcRL4 defines a pro-inflammatory, RANKL-producing B cell subset in rheumatoid arthritis. Ann Rheum Dis. (2015) 74:928-35. doi: 10.1136/annrheumdis-2013-204116

18. Zharhary D. Age-related changes in the capability of the bone marrow to generate B cells. J Immunol. (1988) 141:1863-9.

19. Rossi DJ, Bryder D, Zahn JM, Ahlenius H, Sonu R, Wagers AJ, et al. Cell intrinsic alterations underlie hematopoietic stem cell aging. Proc Natl Acad Sci USA. (2005) 102:9194-9. doi: 10.1073/pnas.0503280102

20. Labrie JE III, Sah AP, Allman DM, Cancro MP, Gerstein RM. Bone marrow microenvironmental changes underlie reduced RAG-mediated recombination and B cell generation in aged mice. J Exp Med. (2004) 200:41123. doi: $10.1084 /$ jem. 20040845

21. Cho RH, Sieburg HB, Mullersieburg CE. A new mechanism for the aging of hematopoietic stem cells: aging changes the clonal composition of the stem cell compartment but not individual stem cells. Blood (2008) 111:5553. doi: 10.1182/blood-2007-11-123547

22. Nipper AJ, Smithey MJ, Shah RC, Canaday DH, Landay AL. Diminished antibody response to influenza vaccination is characterized by expansion of 
an age-associated B-cell population with low PAX5. Clin Immunol. (2018) 193:80-7. doi: 10.1016/j.clim.2018.02.003

23. Stephan RP, Lillelghanian DA, Witte PL. Development of B cells in aged mice: decline in the ability of pro-B cells to respond to IL-7 but not to other growth factors. J Immunol. (1997) 158:1598.

24. Stephan RP, Reilly CR, Witte PL. Impaired ability of bone marrow stromal cells to support B-lymphopoiesis with age. Blood (1998) 91:75-88.

25. Alterwolf S, Blomberg BB, Riley RL. Deviation of the B cell pathway in senescent mice is associated with reduced surrogate light chain expression and altered immature B cell generation, phenotype, and light chain expression. $J$ Immunol. (2009) 182:138. doi: 10.4049/jimmunol.182.1.138

26. Jensen K, Rother MB, Brusletto BS, Olstad OK, Dalsbotten Aass HC, van Zelm MC, et al. Increased ID2 levels in adult precursor B cells as compared with children is associated with impaired Ig locus contraction and decreased bone marrow output. J Immunol. (2013) 191:1210-9. doi: 10.4049/jimmunol.1203462

27. Sigvardsson M, O'Riordan M, Grosschedl R. EBF and E47 Collaborate to Induce Expression of the Endogenous Immunoglobulin Surrogate Light Chain Genes. Immunity (1997) 7:25. doi: 10.1016/S1074-7613(00)80507-5

28. Frasca D, Romero M, Diaz A, Alter-Wolf S, Ratliff M, Landin AM, et al. A molecular mechanism for TNF- $\alpha$-mediated downregulation of B cell responses. J Immunol. (2012) 188:279. doi: 10.4049/jimmunol.1003964

29. Michelle R, Sarah A, Kelly MA, Daniela F, Wright JA, Zinkel SS, et al. In aged mice, low surrogate light chain promotes pro-B-cell apoptotic resistance, compromises the PreBCR checkpoint, and favors generation of autoreactive, phosphorylcholine-specific B cells. Aging Cell (2015) 14:382-90. doi: 10.1111 /acel.12302

30. Rubtsova K, Rubtsov AV, van Dyk LF, Kappler JW, Marrack P. T-box transcription factor T-bet, a key player in a unique type of B-cell activation essential for effective viral clearance. Proc Natl Acad Sci USA. (2013) 110:E3216-E24. doi: 10.1073/pnas.1312348110

31. Knox JJ, Buggert M, Kardava L, Seaton KE, Eller MA, Canaday DH, et al. Tbet $+\mathrm{B}$ cells are induced by human viral infections and dominate the HIV gp140 response. Jci Insight (2017) 2:8. doi: 10.1172/jci.insight.92943

32. McHeyzer-Williams LJ, McHeyzer-Williams MG. Antigen-specific memory B cell development. Annu Rev Immunol. (2005) 23:487-513. doi: 10.1146/annurev.immunol.23.021704.115732

33. Chan TD, Gatto D, Wood K, Camidge T, Basten A, Brink R. Antigen affinity controls rapid $\mathrm{T}$-dependent antibody production by driving the expansion rather than the differentiation or extrafollicular migration of early plasmablasts. J Immunol. (2009) 183:3139-49. doi: 10.4049/jimmunol.0901690

34. Goodnow CC, Adelstein S, Basten A. The need for central and peripheral tolerance in the B cell repertoire. Science (1990) 248:1373-9. doi: $10.1126 /$ science. 2356469

35. Lam KP, Kuhn R, Rajewsky K. In vivo ablation of surface immunoglobulin on mature B cells by inducible gene targeting results in rapid cell death. Cell (1997) 90:1073-83. doi: 10.1016/S0092-8674(00)80373-6

36. Akira $S$. The role of pattern-recognition receptors in innate immunity: update on Toll-like receptors. Nat Immunol. (2010) 11:373. doi: 10.1038/ni.1863

37. Granato A, Hayashi EA, Baptista BJ, Bellio M, Nobrega A. IL-4 regulates Bim expression and promotes B cell maturation in synergy with BAFF conferring resistance to cell death at negative selection checkpoints. J Immunol. (2014) 192:5761-75. doi: 10.4049/jimmunol.1300749

38. Moore PA, Belvedere O, Orr A, Pieri K, Lafleur DW, Feng P, et al. BLyS: member of the tumor necrosis factor family and B lymphocyte stimulator. Science (1999) 285:260-3. doi: 10.1126/science.285.5425.260

39. Hsu BL, Harless SM, Lindsley RC, Hilbert DM, Cancro MP. Cutting edge: BLyS enables survival of transitional and mature B cells through distinct mediators. J Immunol. (2002) 168:5993-6. doi: 10.4049/jimmunol.168.12.5993

40. Naradikian MS, Myles A, Beiting DP, Roberts KJ, Dawson L, Herati RS, et al. Cutting edge: IL-4, IL-21, and IFN- $\gamma$ interact to govern T-bet and CD11c expression in TLR-activated B cells. J Immunol. (2016) 197:1023-8. doi: 10.4049/jimmunol.1600522

41. Peng SL, Szabo SJ, Glimcher LH. T-bet regulates IgG class switching and pathogenic autoantibody production. Proc Natl Acad Sci USA. (2002) 99:5545. doi: $10.1073 /$ pnas.082114899
42. Wang NS, Mcheyzer-Williams LJ, Okitsu SL, Burris TP, Reiner SL, Mcheyzer-Williams MG. Divergent transcriptional programming of classspecific B cell memory by T-bet and ROR $\alpha$. Nat Immunol. (2012) 13:604. doi: $10.1038 /$ ni.2294

43. Kipps TJ, Parham P, Punt J, Herzenberg LA. Importance of immunoglobulin isotype in human antibody-dependent, cell- mediated cytotoxicity directed by murine monoclonal antibodies. J Exp Med. (1985) 161:1-17. doi: 10.1084/jem.161.1.1

44. Sangster MY, Topham DJ, D'Costa S, Cardin RD, Marion TN, Myers LK, et al. Analysis of the virus-specific and nonspecific B cell response to a persistent B-lymphotropic gammaherpesvirus. J Immunol. (2000) 164:1820-8. doi: 10.4049/jimmunol.164.4.1820

45. Myles A, Gearhart PJ, Cancro MP. Signals that drive T-bet expression in B cells. Cell Immunol. (2017) 321:3-7. doi: 10.1016/j.cellimm.2017.09.004

46. Manni M, Gupta S, Ricker E, Chinenov Y, Park SH, Shi M, et al. Regulation of age-associated B cells by IRF5 in systemic autoimmunity. Nat Immunol. (2018) 19:407-19. doi: 10.1038/s41590-018-0056-8

47. Liu Y, Zhou S, Qian J, Wang Y, Yu X, Dai D, et al. T-bet $(+) C D 11 \mathrm{c}(+)$ $B$ cells are critical for antichromatin immunoglobulin $G$ production in the development of lupus. Arthritis Res Ther. (2017) 19:225. doi: 10.1186/s13075-017-1438-2

48. Rubtsov AV, Marrack P, Rubtsova K. T-bet expressing B cells - novel target for autoimmune therapies? Cell Immunol. (2017) 321:35-9. doi: 10.1016/j.cellimm.2017.04.011

49. Rubtsova K, Rubtsov AV, Thurman JM, Mennona JM, Kappler JW, Marrack P. B cells expressing the transcription factor T-bet drive lupuslike autoimmunity. J Clin Invest. (2017) 127:1392. doi: 10.1172/JCI 91250

50. Aranburu A, Hook N, Gerasimcik N, Corleis B, Ren W, Camponeschi A, et al. Age-associatedBcells expanded in autoimmune mice are memory cells sharing H-CDR3-selected repertoires. Eur J Immunol. (2018) 48:509-21. doi: 10.1002/eji.201747127

51. Christensen SR, Shupe J, Nickerson K, Kashgarian M, Flavell RA, Shlomchik MJ. Toll-like receptor 7 and TLR9 dictate autoantibody specificity and have opposing inflammatory and regulatory roles in a murine model of lupus. Immunity (2006) 25:417-28. doi: 10.1016/j.immuni.2006. 07.013

52. Nickerson KM, Christensen SR, Shupe J, Kashgarian M, Kim D, Elkon K, et al. TLR9 regulates TLR7- and MyD88-dependent autoantibody production and disease in a murine model of lupus. J Immunol. (2010) 184:1840-8. doi: 10.4049/jimmunol.0902592

53. Ouyang X, Yang Z, Zhang R, Arnaboldi P, Lu G, Li Q, et al. Potentiation of Th17 cytokines in aging process contributes to the development of colitis. Cell Immunol. (2011) 266:208-17. doi: 10.1016/j.cellimm.2010.10.007

54. Yamada H. Current perspectives on the role of IL-17 in autoimmune disease. J Inflamm Res. (2010) 3:33-44. doi: 10.2147/JIR.S6375

55. Edwards JCW, Szczepanski L, Szechinski J, Filipowicz-Sosnowska A, Emery P, Close DR, et al. Efficacy of B-cell-targeted therapy with rituximab in patients with rheumatoid arthritis. New Engl J Med. (2004) 350:2572-81. doi: 10.1056/Nejmoa032534

56. Hauser SL, Waubant E, Arnold DL, Vollmer T, Antel J, Fox RJ, et al. B-cell depletion with Rituximab in relapsing-remitting multiple sclerosis. New Engl J Med. (2008) 358:676-88. doi: 10.1056/Nejmoa07 06383

57. Gavazzi G, Krause KH. Ageing and infection. Lancet Infect Dis. (2002) 2:659-66. doi: 10.1016/S1473-3099(02)00437-1

Conflict of Interest Statement: The authors declare that the research was conducted in the absence of any commercial or financial relationships that could be construed as a potential conflict of interest.

Copyright (C) $2019 \mathrm{Ma}$, Wang, Mao and Hao. This is an open-access article distributed under the terms of the Creative Commons Attribution License (CC BY). The use, distribution or reproduction in other forums is permitted, provided the original author(s) and the copyright owner(s) are credited and that the original publication in this journal is cited, in accordance with accepted academic practice. No use, distribution or reproduction is permitted which does not comply with these terms. 